\title{
Efficient and Selective Adsorption of Multi-metal Ions Using Sulfonated Cellulose as Adsorbent
}

\author{
Cuihua Dong ${ }^{1,2} \quad$ xiaodong771111@163.com \\ Fulong Zhang ${ }^{1} \quad \underline{\text { zfl363@126.com }}$ \\ Zhiqiang Pang $^{1^{*}} \quad$ zhiqiang8505@126.com \\ Guihua Yang 1 ygh2626@126.com
}

1 College of Graphic Communication and Packaging, Qilu University of Technology, Jinan, 250353, China

2 Tianjin Key Laboratory of Pulp \& Paper, Tianjin University of Science \& Technology, Tianjin, 300457

*Corresponding author e-mail address: Tel: 86053189631168

zhiqiang8505@126.com 


\begin{abstract}
Contamination of heavy metal in wastewater has caused great concerns on human life and health. Developing an efficient material to eliminate the heavy metal ions has been a popular topic in recent years. In this work, sulfonated cellulose (SC) was explored as efficient adsorbent for metal ions in solution. Thermo gravimetric analyzer (TGA), X-ray diffraction (XRD) and Fourier-transform infrared spectrometer (FTIR) first analyzed the characterizations of SC. Subsequently, effects of solution $\mathrm{pH}$, adsorbent loading, temperature and initial metal ion concentration on adsorption performance were investigated. The results showed that sulfonated modification of cellulose could decrease the crystallinity and thermostability of cellulose. Due to its excellent performance of adsorption to metal ions, SC could reach adsorption equilibrium status within as short as $2 \mathrm{~min}$. In multi-component solution, SC can orderly removes $\mathrm{Fe}^{3+}, \mathrm{Pb}^{2+}$ and $\mathrm{Cu}^{2+}$ with excellent selectivity and high efficiency. In addition, SC is a kind of green and renewable adsorbent because it can be easily regenerated by treatment with acid or chelating liquors. The mechanism study shows that the sulfonic group play a major role in the adsorption process.
\end{abstract}

Keywords: sulfonated cellulose; metal ions; adsorption; removal efficiency, desorption

\title{
1 Introduction
}

The rapid industrialization has generated heavy metal contamination, wherein fossil fuel combustion, mining and smelting activities have intensified the invasion of heavy metal into surface and body of underground water (Singha \& Guleria, 2014). Accumulated heavy metals can do harm to environment and human health even at a quite low concentration. To reduce negative effects of heavy metals in water body, many technologies, such as precipitation, chemical oxidation/reduction, membrane filtration, ion-exchange and adsorption, have been employed to remediate heavy metals (Ji et al., 2012; Zewail \& Yousef, 2015; Sakai, Matsuoka, Zinchenko, \& Murata, 2009; Bessbousse, Rhlalou, Verchère, \& Lebrun, 2008). Among these methods, adsorption received more attentions due to its high efficiency, technical flexibility and 
cost-effective, and adsorbents prepared by cellulose and its derivatives has been broadly investigated because of their renewability, sustainability and biodegradability.

Formerly, a variety of chemically modified cellulose have been prepared as adsorbent to remove different metal ions. For example, the cellulose, modified by using maleic anhydride, removes $\mathrm{Hg}^{2+}$ from water with a moderate adsorption capacity (172.5 mg. $\mathrm{g}^{-1}$ ) (Zhou, Jin, Hu, Zhang, \& Ma, 2012). In addition, Hokkanen investigated the adsorption properties of aminopropyltrietho-xysilane (APS) modified cellulose in aqueous solutions containing $\mathrm{Ni}^{2+}, \mathrm{Cu}^{2+}$ and $\mathrm{Cd}^{2+}$ ions, and the maximum removal capacity for $\mathrm{Ni}^{2+}, \mathrm{Cu}^{2+}$ and $\mathrm{Cd}^{2+}$ ions were $2.734,3.150$ and $4.195 \mathrm{mmol} \cdot \mathrm{g}^{-1}$, respectively (Hokkanen et al., 2014). Compared to the other cellulose derivatives, sulfonated cellulose possess the advantages of low cost, easy preparation and low toxicity.

In our previous work (Dong, Zhang, Pang, Liu, \& Zhang, 2013), we have demonstrated that sulfonated cellulose is good adsorbent for $\mathrm{Pb}^{2+}$ from solution. In this paper, we further investigated competitive adsorption mechanism of multi-metal ions using sulfonated cellulose. These efforts were devoted to further elucidate the adsorption mechanism of sulfonated cellulose and to develop novel adsorbent with excellent performance.

\section{Experimental}

\subsection{Material and chemicals}

Microcrystalline cellulose (MCC) was provided by Shanhe pharmaceutical Co., Ltd. of Anhui Province. Sulphur trioxide pyridine complex $\left(\mathrm{SO}_{3}-\mathrm{Py}\right)$ was purchased from Hubei Prosperity Galaxy Chemical Co., Ltd. N, N-dimethylformamide (DMF, chromatographic grade) was obtained from Tianjin Chemicals Co., Ltd. Iron chloride hexahydrate (99\%), copper nitrate trihydrate (99\%), lead nitrate (99\%) and disodium edetate (99\%) were purchased from Tianjin Daomao Chemical Reagent Company. All chemicals were used as received without further purification.

\subsection{Sulfonation of cellulose}


The MCC was dispersed in DMF and stirred (800 rmp) at $40{ }^{\circ} \mathrm{C}$ for $30 \mathrm{~min}$. Then, $\mathrm{SO}_{3}$-Py was added to the solution and stirred vigorously. The modified samples were collected by filtration through ash-free filter paper (Whatman No. 1442 070) on a Buchner funnel and thoroughly washed with absolute ethyl alcohol. Finally, the collected samples were vacuum-dried at $40{ }^{\circ} \mathrm{C}$ for $48 \mathrm{~h}$.

\subsection{Determination of the sulfonation degree of cellulose (DS)}

The DS was determined by elemental analysis of sulfur in a Carlo Erba EA 1108 CHNS analyzer. Elemental analysis of the samples was carried out by triplicate and the mean values are reported. All the determinations showed relative standard deviations below 2\%. The DS was calculated according to Eq (1):

$\mathrm{DS}=(S \% / C \%) /(32 / 72)$

Where $S \%$ and $C \%$ is the percentage of sulfur and carbon on dry basis respectively; 32 is the atomic weight of sulfur and 72 is the total molecular weight of carbon on glucose unit. All the sulfonated cellulose sample used in this paper with a DS of 0.56.

\subsection{Adsorption of heavy metal ions by SC}

Metal ions solution were prepared by dissolution of $\mathrm{Pb}\left(\mathrm{NO}_{3}\right)_{2}, \mathrm{Cu}\left(\mathrm{NO}_{3}\right)_{2}$ and $\mathrm{FeCl}_{3}$ in ultrapure water. The solution $\mathrm{pH}$ was adjusted by $0.1 \mathrm{M} \mathrm{HCl}$ solution. A certain amount of SC and $25 \mathrm{~mL}$ of metal ions solution were added in a flask. Then, the solutions were vigorously mixed (800 rmp) at specified temperature. The equilibrium solutions were centrifuged and the supernatant concentration were determined using inductively coupled plasma-atomic emission spectrometry (ICP-AES, Optima 2000DV). In the case of binary and ternary metal ions adsorption, designated metal ions were added with identical concentration $\left(100 \mathrm{mg} \cdot \mathrm{L}^{-1}\right)$.

The amount of metal ions adsorbed on SC at adsorption equilibrium was calculated according to Eq (2):

$q_{e}=\left(C_{0}-C_{e}\right) \cdot V / m$

where $q_{e}$ is the amount of adopted metal at equilibrium; $C_{0}$ and $C_{e}$ are the initial and equilibrium concentration of metal ions in the solution, respectively; $V$ is the volume of the solution; and $m$ is the amount of SC added in the solution. 
The removal efficiency $(R \%)$ of the adsorbent was calculated according to Eq (3):

$R(\%)=\left(C_{0}-C_{e}\right) / C_{0} \times 100$

\subsection{Desorption and regeneration}

Desorption experiments were conducted using eluents including $0.1 \mathrm{M} \mathrm{HCl}, 0.1$ $\mathrm{M} \mathrm{HNO}_{3}$ and $0.1 \mathrm{M} \mathrm{Na}_{2}$ EDTA. Firstly, adsorption was performed using $50 \mathrm{mg} \mathrm{SC}$ in $100 \mathrm{mg} \cdot \mathrm{L}^{-1}$ metal ions solutions $(25 \mathrm{ml})$ at room temperature for $30 \mathrm{~min}$. Then the spent adsorbents were filtrated from solutions through ash-free filter paper (Whatman No. 1442 070) on a Buchner funnel. Desorption treatment was then carried out by adding $25 \mathrm{~mL}$ of desorption eluent to the adsorbent and vigorously stirred (800 rpm) for $2 \mathrm{~h}$. The desorbed adsorbent was washed thoroughly with distilled water and subjected to the next cycle. The regeneration performances were examined by adsorptiondesorption process for four cycles for $\mathrm{Pb}^{2+}$ ions and the concentration of ions was measured at each step by inductively coupled plasma emission spectrometer as described above.

The regeneration efficiency $\left(\mathrm{R}_{E} \%\right)$ of adsorbent was calculated according to $\mathrm{Eq}(4)$ :

$R_{E}(\%)=\left(C_{0}-C_{r}\right) /\left(C_{0}-C_{e}\right) \times 100$

Where $C_{r}$ is the equilibrium concentration of metal ions in the solution after desorption.

\subsection{Characterization of SC}

Fourier transform infrared spectroscopy (FTIR) was used to analyze groups in the samples obtained by the $\mathrm{KBr}$ pellet technique. Samples were grounded, mixed with $\mathrm{KBr}$, and pressed in an evacuated die under suitable pressure. The spectrum was scanned with wavenumber from 400 to $4000 \mathrm{~cm}^{-1}$.

X-ray diffraction spectroscopy (XRD) with $\mathrm{Cu} \mathrm{K}_{\alpha}$ radiation generated at $45 \mathrm{kV}$ and $40 \mathrm{~mA}$ was used to measure the crystal structure of cellulose. XRD spectra were obtained at a rate of $2{ }^{\circ} \mathrm{C} / \mathrm{min}$ from $5^{\circ}$ to $45^{\circ}$. Thermogravimetric analysis (TGA) were performed under nitrogen purge (TA-Instruments Q-50 thermogravimetric analysis system). The samples were heated from $25{ }^{\circ} \mathrm{C}$ to $500{ }^{\circ} \mathrm{C}$ at rate of $20{ }^{\circ} \mathrm{C} / \mathrm{min}$. 
Based on the procedure described by Sun \& Gunasekaran (2009), we calculated zeta potentials by measuring the electrophoretic mobility with a particle size analyzer (90Plus, Brookhaven, Long Island, NY, USA). The prepared samples were diluted with distilled water. Their concentration typically ranged between $10^{-5}$ and $10^{-2}$ volume fraction prior to zeta potential measurement.

\section{Results and discussion}

\subsection{Characteristics of SC}

\subsubsection{Crystallinity structure of SC}

Cellulose is composed of compact crystalline zone and loose amorphous zone. The ratio between the two zones varies, and significantly affect the reactivity of hydroxyl groups, size and distribution of micropores and adsorption capacity. Characterization of supramolecular alignment of cellulose and its derivatives has been successfully achieved using XRD (Cunha et al., 2007). Thus, the crystalline structure of the original and sulfonated cellulose was analyzed by XRD, whereby illustrated release of free hydroxyl groups and internal permeability derived from sulfonated modification (Fig. 1). Compared to the original cellulose, the relative peak intensity of SC declined significantly due to abundant substitution of hydroxyls of cellulose with sulfonic acid

group (Khalil-bad, Yazdanshenas, \& Nateghi, 2009). Accordingly, crystallinity of sulfonated cellulose $(37.8 \%$ ) was significantly reduced compared to that of the original cellulose $(63.1 \%)$. These results suggested that the sulfonated modification could effectively deconstruct crystalline region and release massive free hydroxyls. 


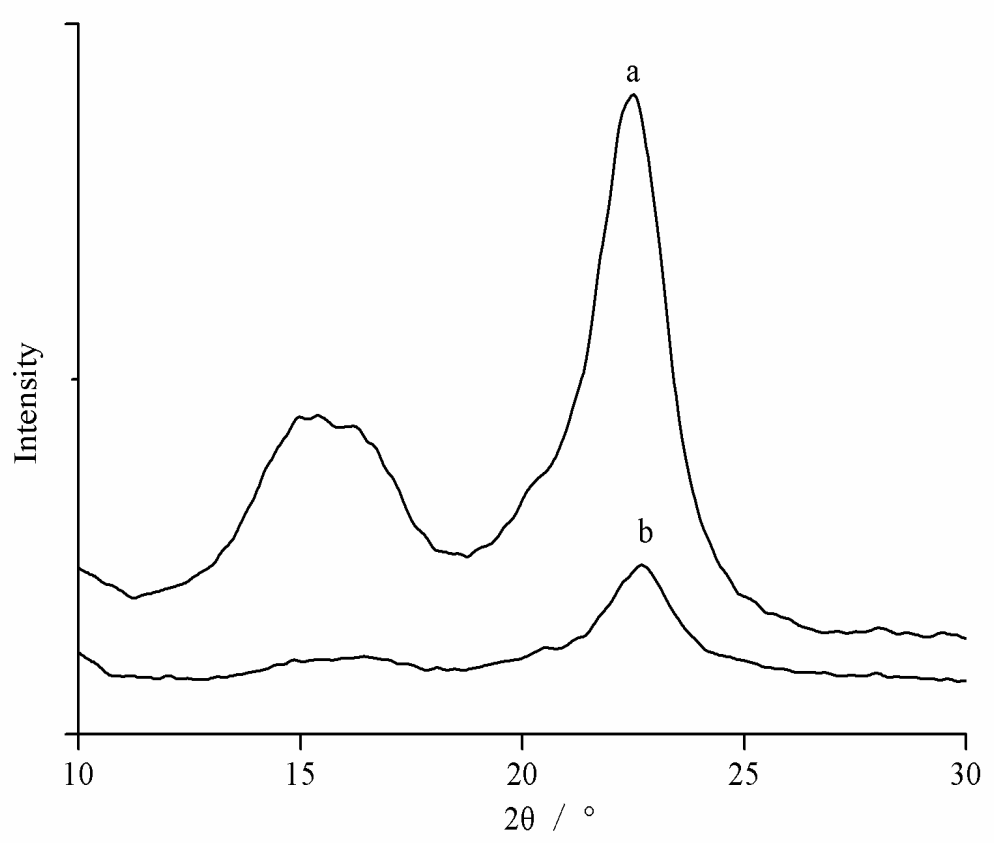

Fig.1. XRD patterns of the original cellulose and sulfonic cellulose (a is the original cellulose; $b$ is the sulfonic cellulose)

\subsubsection{Thermostability of SC}

Thermal properties of adsorbent can be used to evaluate the thermal stability and applicable temperature, which were analyzed using TG with temperature ranged from 25 to $500{ }^{\circ} \mathrm{C}$ (Fig. 2). Compared to the original cellulose, the temperature of substantial weight loss of SC was greatly lowered, which demonstrated the thermostability of cellulose suffered from sulfonated modification. The change of crystallinity and morphology of cellulose derived from sulfonated modification accounted for performance of TG analysis. Essentially, the lower crystallinity originated from abundant disrupture of hydrogen bonds, correspondingly the thermal transformation requires less energy to cleave bonds in adsorbents (Peng, Meng, Ouyang, \& Chang, 2014). 


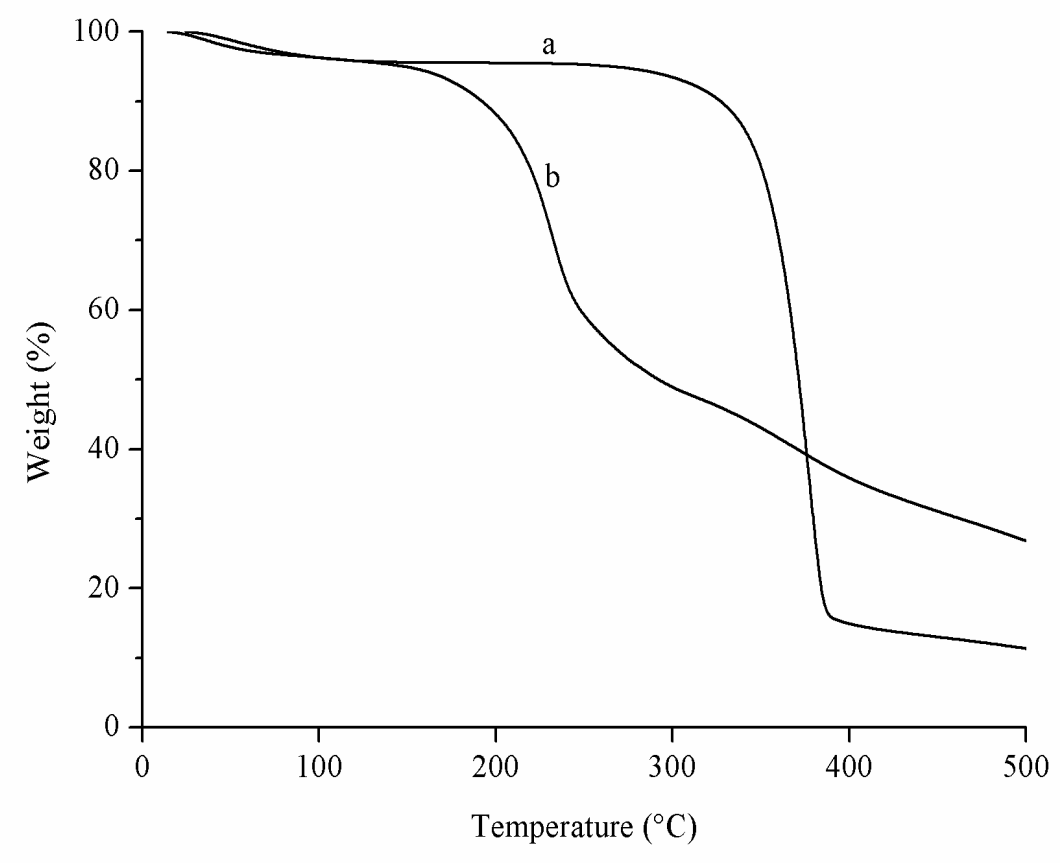

Fig.2. TG curves of cellulose ( $a$ is original cellulose; $b$ is SC).

Furthermore, the main weight loss stage was evidently extended and weight loss rate was reduced after sulfonated modification. Also, the percentage of the residual sulfonic cellulose (35\%) after pyrolysis significantly increased as compared to that of the original cellulose (15\%) (Table 1). Although the initial decomposition temperature of SC was significantly decreased to $150^{\circ} \mathrm{C}$, the utilization of the adsorbent was slightly affected due to the low temperature $\left(<60^{\circ} \mathrm{C}\right)$ for common adsorption operations.

Table 1. Thermal degradation of the original cellulose and sulfonic cellulose

\begin{tabular}{|c|c|c|c|c|}
\hline Sample & ${ }^{\mathrm{a}} \mathrm{IDT}\left({ }^{\circ} \mathrm{C}\right)$ & $\mathrm{T}_{\max }\left({ }^{\circ} \mathrm{C}\right)$ & ${ }^{\mathrm{b}} \mathrm{DI}\left({ }^{\circ} \mathrm{C}\right)$ & Residual mass $400^{\circ} \mathrm{C}(\%)$ \\
\hline $\mathrm{MCC}$ & 300 & 375 & 100 & 15 \\
\hline $\mathrm{SC}$ & 150 & 230 & 150 & 35 \\
\hline
\end{tabular}

Note: ${ }^{\mathrm{a}}$ initial decomposition temperature; ${ }^{\mathrm{b}}$ decomposition interval.

\subsection{Effect of variables on adsorption performance of SC}




\section{(1) Effects of $\mathrm{pH}$}

The distribution of adsorbed metal ions, the surface properties and protonation of functional groups on adsorbent were significantly affected by solution's pH (Sun et al., 2014). Effects of solution's initial $\mathrm{pH}$ on adsorption of metal ions by $\mathrm{SC}$ have been investigated by varying $\mathrm{pH}(1-6)$ at an initial metal ion concentration of $100 \mathrm{mg} \cdot \mathrm{L}^{-1}$. Adsorption properties were not tested for $\mathrm{Fe}^{3+}$ at initial $\mathrm{pH}$ above 4 and $\mathrm{Cu}^{2+}$ and $\mathrm{Pb}^{2+}$ at initial $\mathrm{pH}$ above 6, wherein formation of metal hydroxide was supposed to be precipitated (Dong et al., 2013; Ahmed, 2011). Our experimental results show that the removal efficiency of the metal ions varied significantly with solution's $\mathrm{pH}$ for similar tendency (Fig. 3). Specifically, higher adsorption capacity of metal ions on SC was favored by ascending $\mathrm{pH}$ of the solution. Lower $\mathrm{pH}$ of solution would provide higher concentration of hydronium ions, which strongly compete with metal ions for adsorption sites leading decreasing adsorption sites of adsorbent. Moreover, the availability of $-\mathrm{SO}_{3}{ }^{-}$was decreased at lower $\mathrm{pH}$ for right shift of ionization equilibrium Eq. (5) (Dong et al., 2013).

Cellulose- $\mathrm{SO}_{3}{ }^{-}+\mathrm{H}^{+} \rightleftarrows$ Cellulose- $\mathrm{SO}_{3} \mathrm{H}$

The negatively charged $-\mathrm{SO}_{3}{ }^{-}$groups were inclined to bind positive metal ions via interaction. Thus, the adsorption capacity of SC decreased at lower $\mathrm{pH}$ values for reduced adsorption sites. However, the competition between $\mathrm{H}^{+}$and metal ions for adsorption sites become less significant with an increasing $\mathrm{pH}$, and the available sites of $-\mathrm{SO}_{3}{ }^{2-}$ increased for left shift of ionization equilibrium. Thus, more adsorption sites of $\mathrm{SC}$ were exposed at higher $\mathrm{pH}$ value. Correspondingly, the optimal initial $\mathrm{pH}$ for adsorption could be established ( $\mathrm{pH} 4$ for $\mathrm{Fe}^{3+}$, and $\mathrm{pH} 6$ for $\mathrm{Cu}^{2+}$ and $\mathrm{Pb}^{2+}$ ), where maximum adsorption efficiency could be achieved, avoiding the chemical precipitation of metal ions. 


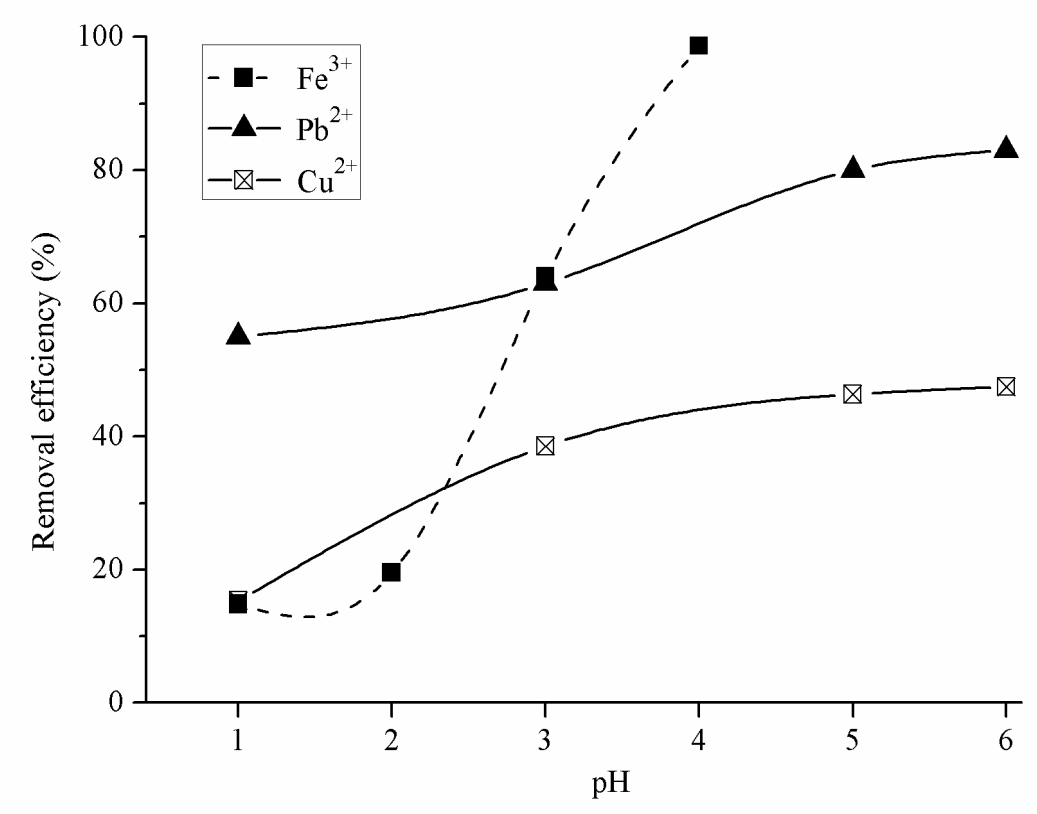

Fig.3 Effect of $\mathrm{pH}$ on the adsorption of metal ions (initial concentration of metal ions is $100 \mathrm{mg} \cdot \mathrm{L}^{-1}, 25 \mathrm{~mL}$ metal ions solution, $\mathrm{SC}$ loading $50 \mathrm{mg}$; residence time of $30 \mathrm{~min}$; temperature at $25^{\circ} \mathrm{C}$ ).

(2) Effect of adsorbent loading

Effect of SC loading on adsorption performance of metal ions was investigated at adsorbent loading ranged between 25 to $200 \mathrm{mg}$ (Fig. 4). Unsurprisingly, the higher removal efficiency of metal ions could be achieved with the increase of adsorbent loading for all the investigated metal ions. Generally, large amount of adsorbent in adsorption process could guarantee availability of more adsorption sites, which contribute to high adsorption capacity. Moreover, the removal efficiency as a function of adsorbent loading varied significantly with metal ions. For example, $\mathrm{Fe}^{3+}$ can be readily adsorbed, and almost $100 \%$ removal efficiency could be achieved even at adsorbent loading as low as $25 \mathrm{mg}$. However, at identical adsorbent loading $(25 \mathrm{mg})$, the removal efficiency of $\mathrm{Pb}^{2+}(50 \%)$ and $\mathrm{Cu}^{2+}(30 \%)$ were significantly lowered. On the other hand, the removal efficiency of $\mathrm{Cu}^{2+}$ increased slowly with adsorbent loading as compared to that of $\mathrm{Pb}^{2+}$, which may due to the weak interaction between $\mathrm{Cu}^{2+}$ and adsorbent. In contrast, the 
removal efficiency of $\mathrm{Cu}^{2+}$ at adsorbent loading of $200 \mathrm{mg}$ can be close to that of $\mathrm{Pb}^{2+}$ at adsorbent loading of $100 \mathrm{mg}$. Thus, high loading of adsorbent is required for $\mathrm{Cu}^{2+}$ adsorption.

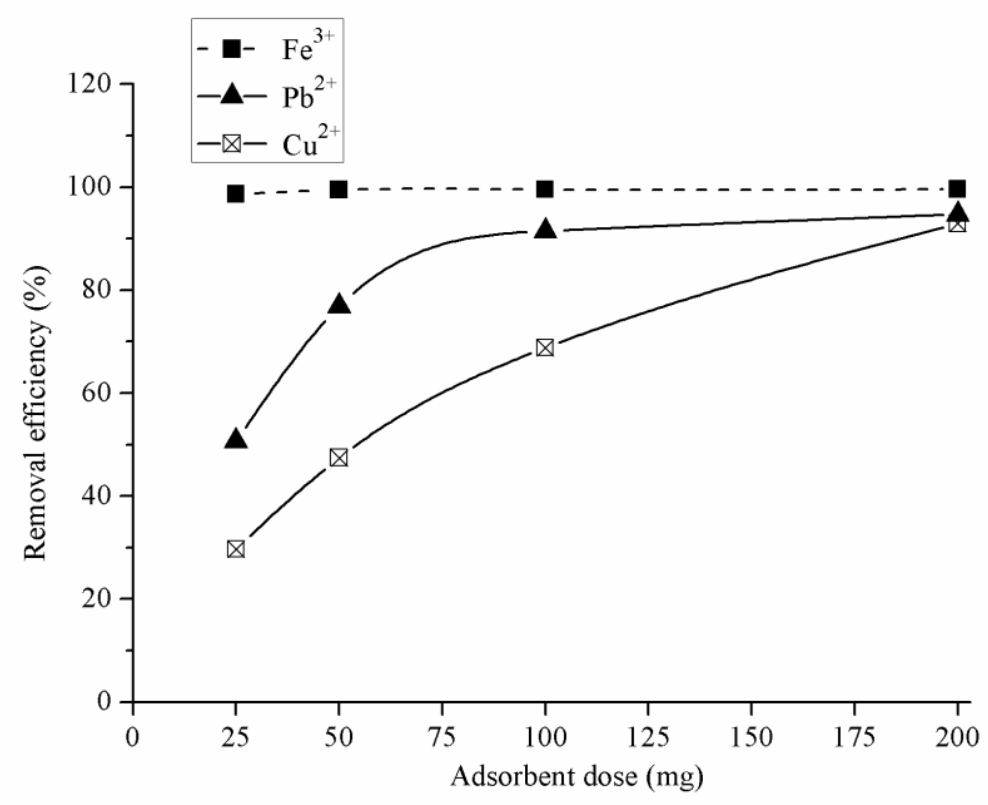

Fig.4 Effect of adsorbent loading on the absorption of $\mathrm{Fe}^{3+}, \mathrm{Pb}^{2+}$ and $\mathrm{Cu}^{2+}$ by $\mathrm{SC}$ (metal ions concentration, $100 \mathrm{mg} \cdot \mathrm{L}^{-1}$; volume of metal ions, $25 \mathrm{~mL}$; residence time of $30 \mathrm{~min}$; temperature $25{ }^{\circ} \mathrm{C}$; $\mathrm{pH}$ of $\mathrm{Fe}^{3+}$ solution, $4 ; \mathrm{pH}$ of $\mathrm{Pb}^{2+}$ and $\mathrm{Cu}^{2+}$ solution, 6 )

(3) Effects of temperature

Effect of temperature $\left(25-65{ }^{\circ} \mathrm{C}\right)$ on adsorption of metal ions by SC was investigated at initial concentration of metal ion of $100 \mathrm{mg} \cdot \mathrm{L}^{-1}$ (Fig.5). $\mathrm{Fe}^{3+}$ was nearly completely adsorbed at $\mathrm{pH}$ above 3 , and variation of removal efficiency was negligible at different temperatures. Thus, $\mathrm{pH}$ of 3 for $\mathrm{Fe}^{3+}$ solution was used to investigate effect of temperature on adsorption. As shown in Fig. 5, the removal efficiency of metal ions increased as a function of temperature, indicating that the adsorption process was endothermic. Also, the molecular motion in the process of adsorption could be accelerated at higher temperature, therefore, the time for adsorption equilibrium could be reduced. 


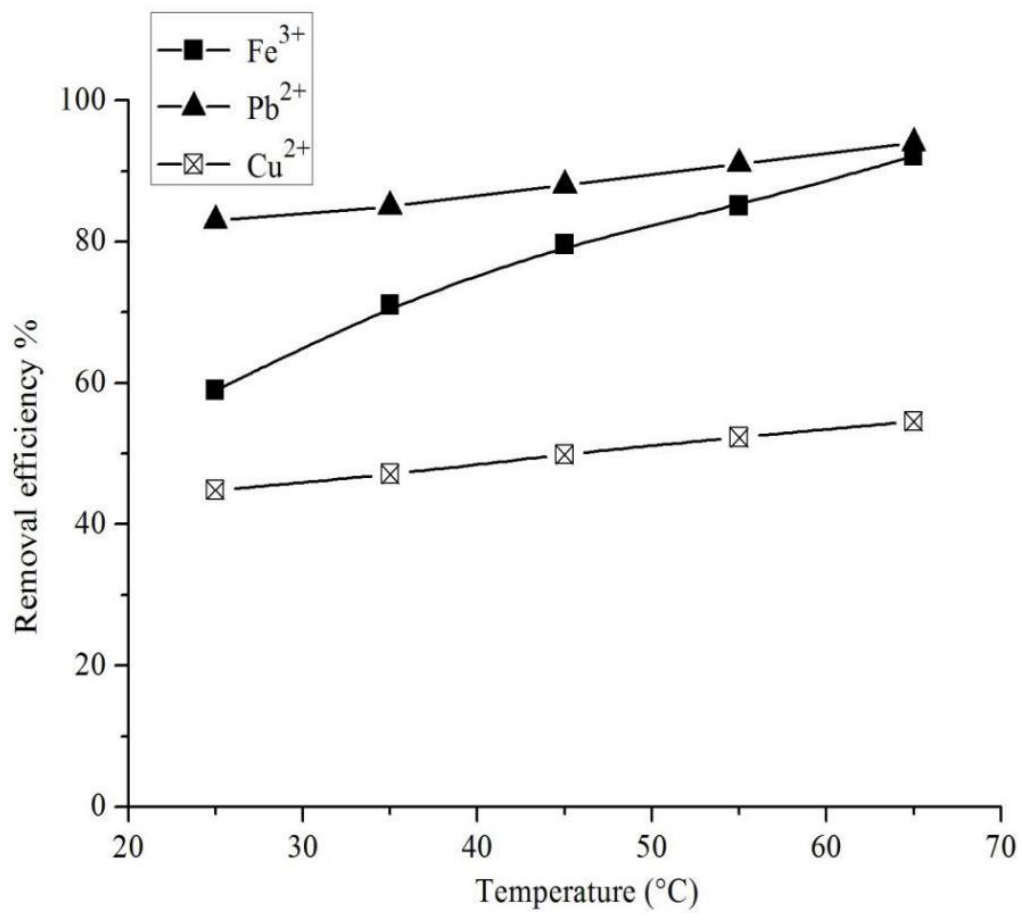

Fig.5 Effect of temperature on the absorption: (initial concentration of metal ions, 100 $\mathrm{mg} \cdot \mathrm{L}^{-1}$; volume of metal ions, $25 \mathrm{~mL}$; $\mathrm{SC}$ dose, $50 \mathrm{mg}$; contact time, $30 \mathrm{~min}$; $\mathrm{pH}$ of $\mathrm{Fe}^{3+}$ solution, $4 ; \mathrm{pH}$ of $\mathrm{Pb}^{2+}$ and $\mathrm{Cu}^{2+}$ solution, 6 )

(4) Effect of initial metal ion concentration

Effect of initial metal ion concentration on adsorption by SC was investigated by varying metal ion concentration from 20 to $200 \mathrm{mg} \cdot \mathrm{L}^{-1}$. As shown in Fig. 6, the removal efficiency of $\mathrm{Pb}^{2+}$ and $\mathrm{Cu}^{2+}$ gradually decreased with the increase of initial concentration of metal solution, whereas the removal efficiency of $\mathrm{Fe}^{3+}$ changed little under the same conditions. Typically, high concentration of reactants leads to shift direction of reaction to products. Therefore, the amount of adsorbed metal ions by SC increased with the increase of initial concentration for all studied metal ions. 


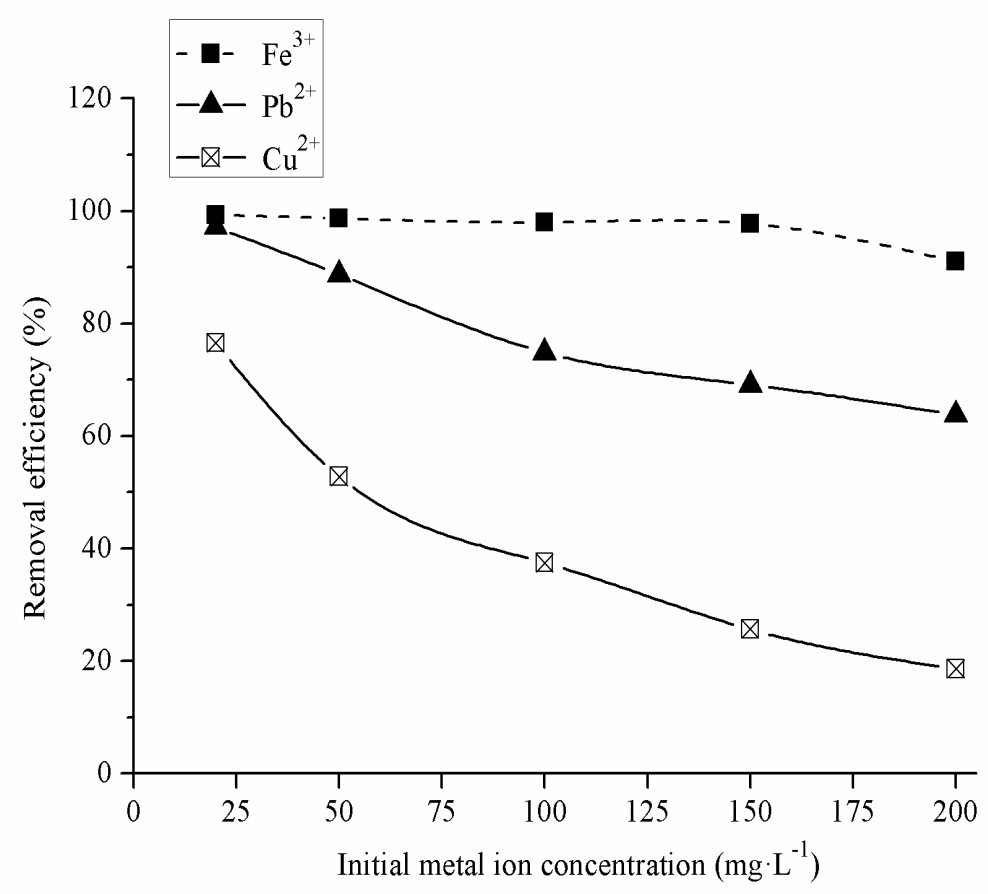

Fig.6 Effect of initial metal concentration on the absorption: (volume of metal ions, 25 $\mathrm{mL}$; SC dose, $50 \mathrm{mg}$; contact time, $30 \mathrm{~min}$; temperature, $25^{\circ} \mathrm{C}$; $\mathrm{pH}$ of $\mathrm{Fe}^{3+}$ solution, 4; $\mathrm{pH}$ of $\mathrm{Pb}^{2+}$ and $\mathrm{Cu}^{2+}$ solution, 6 )

\section{(5) Effect of contact time}

The equilibrium time is an important factor for an economical adsorption system, Effect of contact time on adsorption of metal ions by SC was investigated by varying contact time from $2 \mathrm{~min}$ to $20 \mathrm{~min}$ (Fig.7). The potential maximum adsorption capacity of SC on different metals could be readily reached. During the first $2 \mathrm{~min}$, the removal efficiencies for $\mathrm{Fe}^{3+}, \mathrm{Pb}^{2+}$ and $\mathrm{Cu}^{2+}$ were $97 \%, 84 \%$ and $40 \%$ respectively. And removal efficiencies were nearly unchanged when contact time is greater than $2 \mathrm{~min}$. The contact time for maximum adsorption is extremely shorter than that of the reported absorbents based on lignocellulosic materials (Zhou et al., 2015; Liu et al., 2015; Zhou et al., 2014; Peng et al., 2014). Thus, extension of contact time has a little effect on adsorption performance, and rapid adsorption of metal ions is feasible with SC application. 


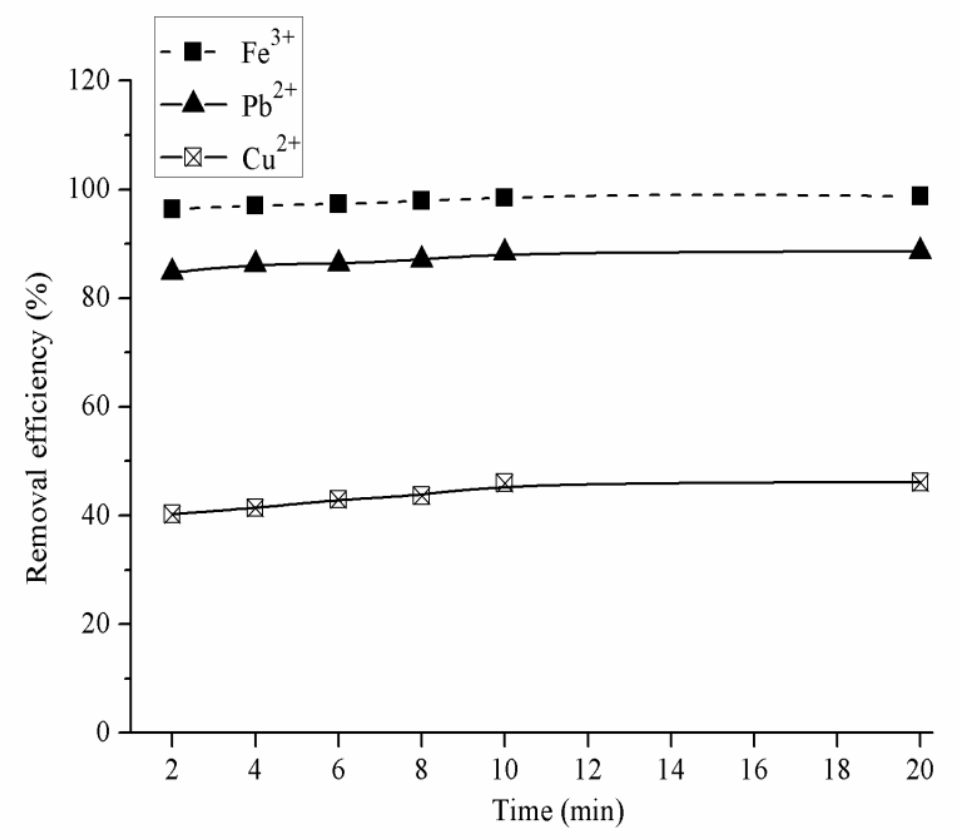

Fig.7 Effect of contact time on the absorption: (volume of metal ions, $25 \mathrm{~mL}$; initial concentration of metal ions, $100 \mathrm{mg} \cdot \mathrm{L}^{-1}$; $\mathrm{SC}$ dose, $50 \mathrm{mg}$; temperature, $25^{\circ} \mathrm{C}$; $\mathrm{pH}$ of $\mathrm{Fe}^{3+}$ solution, 4; $\mathrm{pH}$ of $\mathrm{Pb}^{2+}$ and $\mathrm{Cu}^{2+}$ solution, 6 )

\subsection{Multi-component adsorption}

Generally, multi-component metal ions in effluent are required to be adsorbed in industrial process (Cunha et al., 2007). Compared to single-metal ion, adsorption of multi-metal ions by adsorbent would be quite different (Sehaqui et al., 2014). Therefore, adsorption process and adsorption selectivity of multi-component solution by SC are necessarily to be elucidated. The removal capacity of SC for each metal ion using binary and ternary solutions were investigated for understanding the competitive effects in multi-component solutions, and results was shown in Fig. 8. The adsorption of $\mathrm{Fe}^{3+}$ was conducted with initial solution $\mathrm{pH}$ of 4 to prevent precipitation of iron hydroxide. The adsorption experiments of $\mathrm{Pb}^{2+}$ and $\mathrm{Cu}^{2+}$ was conducted with the initial $\mathrm{pH}$ of 6.

The competition between metal ions led to the decrease of the adsorption capacity for a specified metal ion. When individual metal ion was adsorbed by SC, removal efficiencies for $\mathrm{Fe}^{3+}, \mathrm{Pb}^{2+}$ and $\mathrm{Cu}^{2+}$ were $98.7 \%, 83.0 \%$ and $47.5 \%$, respectively. 
However, as compared to single-metal ion adsorption, removal efficiencies for these metal irons all decreased with varying extent in the presence of competitive metal ions. In binary-metal ions solutions, the removal efficiency of $\mathrm{Fe}^{3+}$ in the presence of $\mathrm{Cu}^{2+}$ and $\mathrm{Pb}^{2+}$ were slightly reduced from $98.7 \%$ to $87.2 \%$ and $84.6 \%$, respectively. However, the removal efficiency of $\mathrm{Cu}^{2+}$ and $\mathrm{Pb}^{2+}$ in the presence of $\mathrm{Fe}^{3+}$ were significantly reduced to $13.3 \%$ and $17.2 \%$, respectively. These results indicate that $\mathrm{Fe}^{3+}$ could be preferentially adsorbed by $\mathrm{SC}$ compared to $\mathrm{Cu}^{2+}$ and $\mathrm{Pb}^{2+}$. In the $\mathrm{Cu}^{2+}-\mathrm{Pb}^{2+}$ binary solution, the removal efficiency of $\mathrm{Cu}^{2+}$ and $\mathrm{Pb}^{2+}$ also decreased to $24.4 \%$ and $67.3 \%$ respectively, suggesting $\mathrm{Pb}^{2+}$ has stronger affinity on $\mathrm{SC}$ as compared to $\mathrm{Cu}^{2+}$. In the ternary-metal ions system, the removal efficiency of $\mathrm{Fe}^{3+}$ was slightly reduced to $83.3 \%$, while the adsorption of $\mathrm{Pb}^{2+}$ and $\mathrm{Cu}^{2+}$ were substantially repressed in the presence of $\mathrm{Fe}^{3+}$, and the removal efficiency of $\mathrm{Cu}^{2+}$ and $\mathrm{Pb}^{2+}$ were reduced to $13.1 \%$ and $16.1 \%$, respectively. The decrease in adsorption capacity of individual metal ion by SC in multi-heavy metal ions solution may attribute to competitive adsorption and less availability of binding sites.

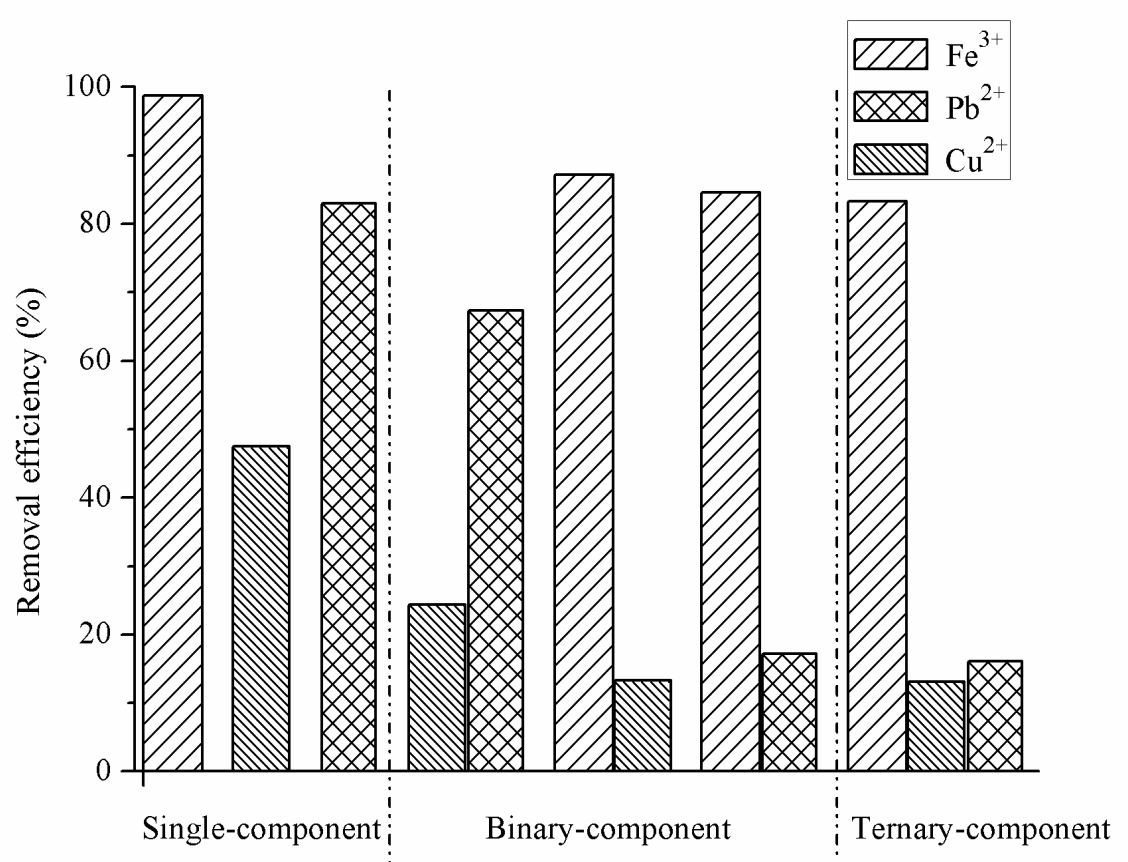

Fig.8 Removal of metal ions from single, binary and ternary mixtures (each metal concentration, $100 \mathrm{mg} \cdot \mathrm{L}^{-1}$; volume of metal ions solution, $25 \mathrm{~mL}$; adsorbents, $50 \mathrm{mg}$; 
contact time, $30 \mathrm{~min}$; temperature, $25^{\circ} \mathrm{C}$ ).

Results from multi-component adsorption showed that the adsorption performance of $\mathrm{Fe}^{3+}$ was slightly affected in the presence of $\mathrm{Pb}^{2+}$ and $\mathrm{Cu}^{2+}$, whereas the adsorption of $\mathrm{Cu}^{2+}$ and $\mathrm{Pb}^{2+}$ was significantly reduced when in a competitive metal ions mixtures. As mentioned above, the order of removal efficiency for the three metal ions was $\mathrm{Fe}^{3+}$ $\mathrm{Pb}^{2+}-\mathrm{Cu}^{2+}$, implying the $\mathrm{Fe}^{3+}$ can be effectively separated from $\mathrm{Pb}^{2+}$ and $\mathrm{Cu}^{2+}$ by $\mathrm{SC}$.

\subsection{Desorption and regeneration performance of SC}

Adsorbent's reusability is one of the crucial factors for evaluating its potential commercial applications. Desorption is necessary to restore the original adsorption capacity of adsorbent, and thus recover valuable metals from wastewater. As indicated in the ionic equilibrium equation (Eq. (5)), metal ions can be desorbed from SC by adding acid. In addition, EDTA as desorption reagent was widely used in desorption for its powerful chelating capability on metal ions. Thus, desorption of $\mathrm{Pb}^{2+}, \mathrm{Cu}^{2+}$ and $\mathrm{Fe}^{3+}$ ions from SC was investigated using $0.1 \mathrm{M} \mathrm{HCl}, 0.1 \mathrm{M} \mathrm{HNO}_{3}$ and $0.1 \mathrm{M} \mathrm{Na}_{2}$ EDTA (Fig. 9) as eluent. The desorption performance was evaluated for various metal ions at the identical conditions.

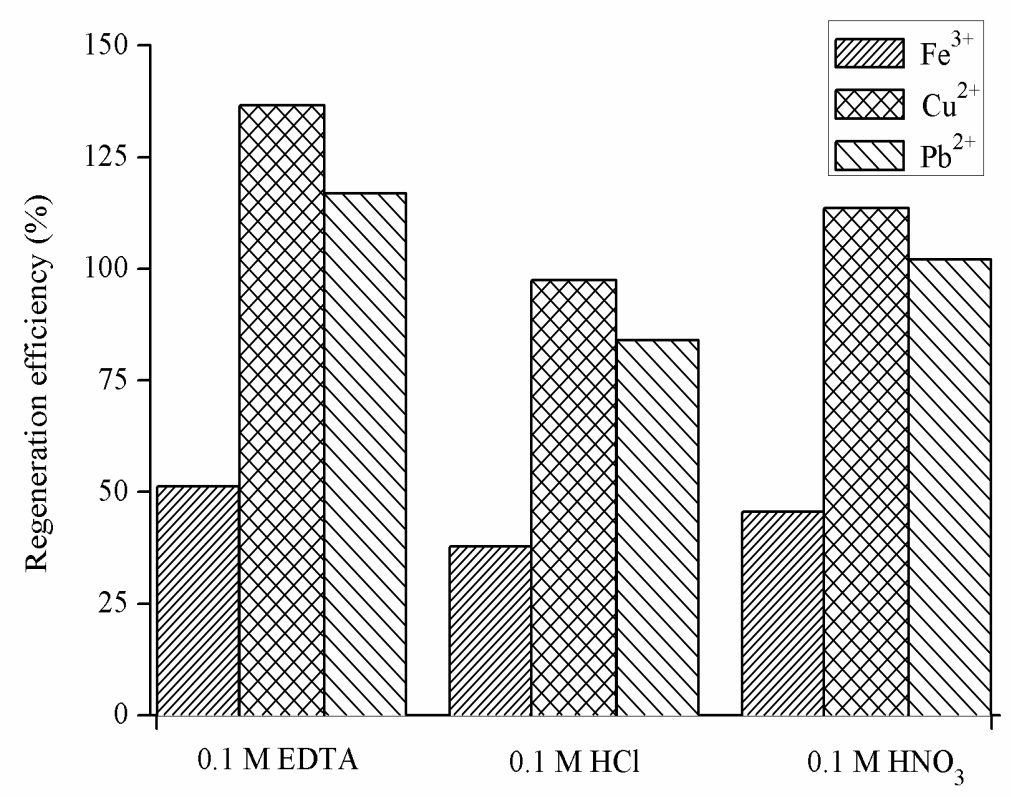

Fig.9 Effect of desorption eluent on the regeneration of adsorbent (metal concentration, 
$100 \mathrm{mg} \cdot \mathrm{L}^{-1}$; adsorbent dose, $50 \mathrm{mg}$; volume of desorption eluent, $25 \mathrm{~mL}$ ).

All investigated desorption eluents showed excellent desorption efficiency for $\mathrm{Pb}^{2+}$ and $\mathrm{Cu}^{2+}$. However, desorption of $\mathrm{Fe}^{3+}$ from $\mathrm{SC}$ was difficult to achieve as compared to $\mathrm{Pb}^{2+}$ and $\mathrm{Cu}^{2+}$, for its strong affinity to adsorbent as described above. Furthermore, the regeneration efficiency of adsorbent for metal ions in all eluents follows in the order $\mathrm{Cu}^{2+}, \mathrm{Pb}^{2+}, \mathrm{Fe}^{3+}$, which is in consistent with its affinity to absorbent. Generally, the bonding between the active sites of adsorbent and metal ions is not strong enough to be retained in acidic conditions (Nassar, 2010). Moreover, $\mathrm{Na}_{2}$ EDTA solution could desorb metal ions more efficiently than $\mathrm{HNO}_{3}$ and $\mathrm{HCl}$. Na2 EDTA was believed to possess strong coordination ability on metal ions, resulting in the metal ions more easily to be desorbed (Yu et al., 2011). Therefore, $0.1 \mathrm{M} \mathrm{Na}_{2}$ EDTA solution was chosen for excellent regeneration reagent of SC.

The reusability was checked by following the adsorption-desorption process for four cycles for $\mathrm{Pb}^{2+}$ ions. The adsorption efficiency in each cycle was analyzed (Fig. 10). The SC kept in good adsorption capability after repeated adsorption-regeneration cycles with negligible changes, indicating that there are almost no irreversible sites on the surface of SC. Our recyclability studies suggest that SC can be repeatedly used as efficient adsorbents in wastewater treatment.

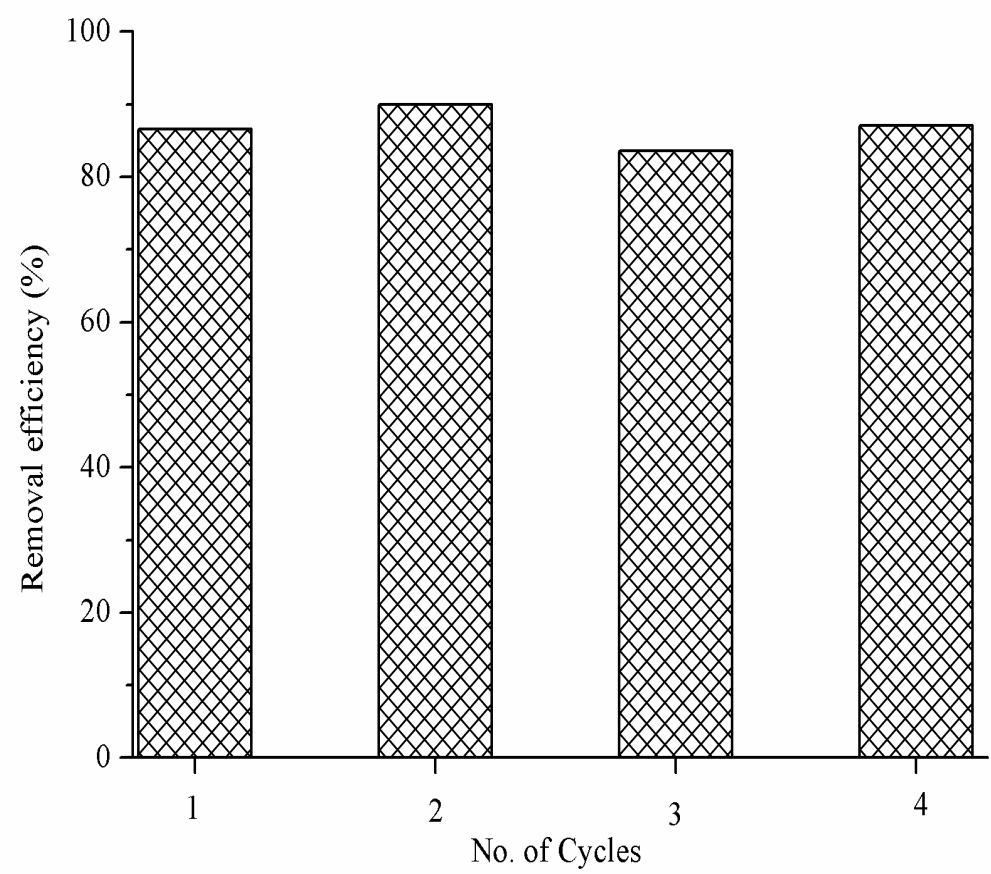

Fig.10 Four consecutive adsorption-desorption cycles of $\mathrm{SC}$ for $\mathrm{Pb}$ (II) (initial 
concentration, $100 \mathrm{mg} \cdot \mathrm{L}^{-1}$; desorption eluent, $25 \mathrm{~mL}$ of $0.1 \mathrm{M}$ EDTA).

\subsection{Adsorption mechanism of SC to metal ions}

To determine the main groups of SC in metal ions adsorption for mechanism assessment, FTIR spectra was employed to analyze the spectra vibration before and after metal ions loaded (Fig.11). The observed characteristic peaks of original cellulose include the broad strong absorption band of O-H stretching vibration (between 3000 and $3700 \mathrm{~cm}^{-1}$ ), C-H stretching vibration (between 2700 and $3000 \mathrm{~cm}^{-1}$ ), the $\mathrm{C}-\mathrm{H}$ rocking vibration at $1386 \mathrm{~cm}^{-1}$ and C-O stretching vibration for cellulose ring at 1120 $\mathrm{cm}^{-1}$. As compared to the original cellulose, the new strong absorptions band (attributing to asymmetrical $\left(1258 \mathrm{~cm}^{-1}\right)$ and symmetrical $\left(1057 \mathrm{~cm}^{-1}\right) \mathrm{S}-\mathrm{O}$ stretching vibrations) were observed in SC. The new absorption band at $813 \mathrm{~cm}^{-1}$ was attributed to the symmetrical $\mathrm{C}-\mathrm{O}-\mathrm{S}$ vibration assigned to a $\mathrm{C}-\mathrm{O}-\mathrm{SO}_{3}$ group.

As compared to original SC, intensities of S-O stretching vibrations band at 1258 $\mathrm{cm}^{-1}$ and $1057 \mathrm{~cm}^{-1}$ were significantly decreased after adsorption, indicating that the sulfonic group may be the main groups responsible for the adsorption of metal ions. However, the absorption bands of hydroxyl group, including wide stretching vibration between 3700 and $3000 \mathrm{~cm}^{-1}$ and sharp bending vibration around $1630 \mathrm{~cm}^{-1}$ were nearly unchanged, indicating infinitesimal adsorption between metal ions and hydroxyl groups. Moreover, the functional band of $1258 \mathrm{~cm}^{-1}, 1057 \mathrm{~cm}^{-1}$ and $813 \mathrm{~cm}^{-1}$ make a slight shift, implying that a chelation process took place between functional groups and metal ions for the electro-static interactions were too weak to vary the band of the functional groups on the surface. This result was consistent with our previous study, in which the adsorption isotherm of $\mathrm{Pb}^{2+}$ was proved closely fitted with Temkin isotherm model, suggesting that the adsorption of metal ions on SCL can be regarded as chemical adsorption. The above-mentioned results suggested that adsorption derived from sulfonic groups may play a significant role on adsorption of metal ions. 


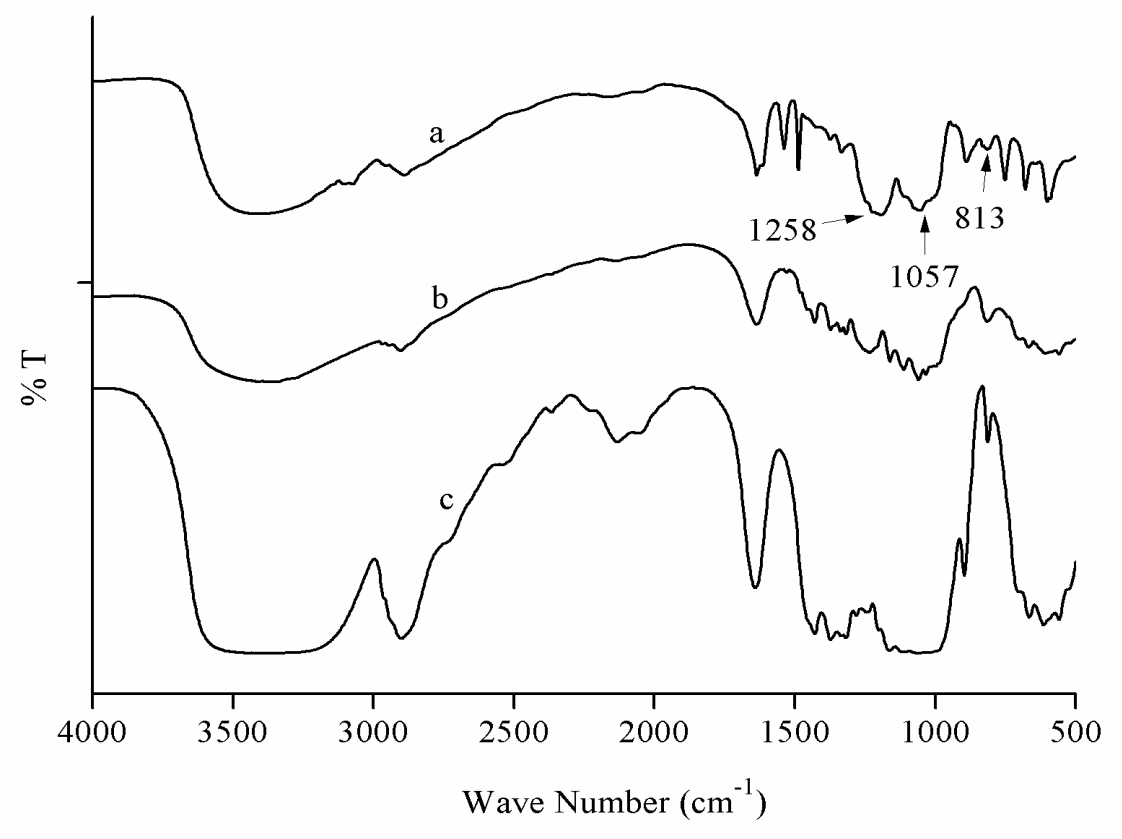

Fig. 11. FTIR spectra of different cellulosic samples (a is sulfonated cellulose; $b$ is sulfonated cellulose after $\mathrm{Fe}^{3+}$ adsorption; $\mathrm{c}$ is the original cellulose).

To further discuss the mechanism of SC adsorption to metal ions, the surface charge of SC were evaluated by zeta potential. The zeta potential negativity of the original cellulose $(-14.3 \mathrm{mV})$ increased to $-37.9 \mathrm{mV}$ after the sulfonated modification indicating the sulfonic group was successfully grafted to cellulose and large quantity of sulfonic anions were exposed. However, the zeta potential of sulfonated cellulose after adsorption of $\mathrm{Fe}^{3+}, \mathrm{Pb}^{2+}$ and $\mathrm{Cu}^{2+}$ was significantly decreased to $-6.24 \mathrm{mV},-9.7 \mathrm{mV}$ and $-14.4 \mathrm{mV}$, respectively, which further confirmed that the interactions between metal ions and sulfonic group on the surface of cellulose were the main interaction forces in the adsorption process. This is also supported by the multi component adsorption studies, which show the removal efficiency of adsorbent for $\mathrm{Fe}^{3+}$ is higher than $\mathrm{Cu}^{2+}$ and $\mathrm{Pb}^{2+}$ and suggest the interactions between $\mathrm{Fe}^{3+}$ and adsorbent is stronger than $\mathrm{Cu}^{2+}$ and $\mathrm{Pb}^{2+}$ due to the high positive charge of $\mathrm{Fe}^{3+}$.

\section{Conclusion}

A new promising absorbent for removal of metal ions in effluent were successful 
developed. The adsorption performance of SC was found to be greatly dependent on solution $\mathrm{pH}$, adsorbent loading, temperature and initial metal ion concentration. Compared to other lignocellulosic adsorbent, SC showed much superiority on adsorption rate. The excellent adsorption behaviors were dominated by sulfonic group. In addition, SC can be easily desorbed after adsorption of metal ions and can be repeatedly used as efficient adsorbent for the removal of metal ions.

\section{Acknowledgments}

The authors are grateful for the financial supports from the National Science Foundation of China (31100434), Natural Science Foundation of Shandong Province (ZR2015CM006), Foundation of Tianjin Key Laboratory of Pulp \& Paper (No. 201305) and Special Fund of Taishan Scholar Project.

\section{References}

1. Ahmed, S. A. (2011). Batch and fixed-bed column techniques for removal of $\mathrm{Cu}(\mathrm{II})$ and $\mathrm{Fe}(\mathrm{III})$ using carbohydrate natural polymer modified complexing agents. Carbohydrare Polymers, 83, 1470-1478.

2. Bessbousse, H., Rhlalou, T., Verchère, J. F., \& Lebrun, L. (2008). Removal of heavy metal ions from aqueous solutions by filtration with a novel complexing membrane containing poly(ethyleneimine) in a poly(vinyl alcohol) matrix. Journal of Membrane Science, 307, 249-259.

3. Cunha, A. G., Freire, C. S. R., Silvestre, A. J. D., Neto, C. P., Gandini, A., Orblin, E., et al. (2007). Characterization and evaluation of the hydrolytic stability of trifluoroacetylated cellulose fibers. Journal of Colloid and Interface Science, 316, 360-366.

4. Dong, C. H., Zhang, H. G., Pang, Z. Q., Liu, Y., \& Zhang, F. L. (2013). Sulfonated modification of cotton linter and its application as adsorbent for high-efficiency 
removal of lead(II) in effluent. Bioresource Technology, 146, 512-518.

5. Hokkanen, S., Rope, E., Suopajärvi, T., Liimatainen, H., Niinimaa, J., \& Sillanpää, M. (2014). Adsorption of $\mathrm{Ni}(\mathrm{II}), \mathrm{Cu}(\mathrm{II})$ and $\mathrm{Cd}(\mathrm{II})$ from aqueous solutions by amino modified nanostructured microfibrillated cellulose. Cellulose, 21, 14711487.

6. Ji, F., Li, C. L., Tang, B., Xu, J. H., Lu, G., \& Liu, P. (2012). Preparation of cellulose acetate/zeolite composite fiber and its adsorption behavior for heavy metal ions in aqueous solution. Chemical Engineering Journal, 209, 325-333.

7. Khalil-Abad, M. S., Yazdanshenas, M. E., \& Nateghi, M. R. (2009). Effect of cationization on adsorption of silver nanoparticles on cotton surfaces and its antibacterial activity. Cellulose, 16, 1147-1157.

8. Liu, L., Gao, Z. Y., Su, X. P., Chen, X., Jiang, L., \& Yao,J. M. (2015). Adsorption Removal of Dyes from Single and Binary Solutions Using a Cellulose-based Bioadsorbent. ACS Sustainable Chemistry \& Engineering, 3, 432-442.

9. Nassar, N. N. (2010). Rapid removal and recovery of $\mathrm{Pb}(\mathrm{II})$ from wastewater by magnetic nanoadsorbents. Journal of Hazardous Materials, 184, 538-546.

10. Peng, S., Meng, H. C., Ouyang, Y., \& Chang, J. (2014). Nanoporous Magnetic Cellulose-Chitosan Composite Microspheres: Preparation, Characterization, and Application for $\mathrm{Cu}(\mathrm{II})$ Adsorption. Industrial and Engineering Chemistry Research, 53, 2106-2113.

11. Sakai, H., Matsuoka, S., Zinchenko, A. A., \& Murata, S. (2009). Removal of heavy metal ions from aqueous solutions by complexation with DNA and precipitation with cationic surfactant. Colloids and Surfaces A: Physicochemical and Engineering Aspects, 347, 210-214.

12. Sehaqui, H., Larraya, U. P. D., Liu, P., Pfenninger, N., Mathew, A. P., Zimmermann, T., et al. (2014). Enhancing adsorption of heavy metal ions onto biobased nanofibers from waste pulp residues for application in wastewater treatment. Cellulose, 21, 2831-2844.

13. Singha, A. S., \& Guleria, A. (2014). Chemical modification of cellulosic 
biopolymer and its use in removal of heavy metal ions from wastewater. Int. J. Biol. Macromol, 67, 409-417.

14. Sun, C. H., \& Gunasekaran, S. (2009). Effects of protein concentration and oilphase volume the stability and rheology of menhaden oil-in-water emulsions stabilize fraction by whey protein isolate with xanthan gum. Food Hydrocolloids, $23,165-174$.

15. Sun, X. T., Yang, L. R., Li, Q., Zhao, J. M., Li, X. P., Wang, X. Q., et al. (2014). Amino-functionalized magnetic cellulose nanocomposite as adsorbent for removal of $\mathrm{Cr}(\mathrm{VI})$ : Synthesis and adsorption studies. Chemical Engineering Journal, 241,175-183.

16. Yu, L., Zou, R. J., Zhang, Z. Y., Song, G. S., Chen, Z. G., Yang, J. M., et al. (2011). A $\mathrm{Zn}_{2} \mathrm{GeO}_{4}$-ethylenediamine hybrid nanoribbon membrane as a recyclable adsorbent for the highly efficient removal of heavy metals from contaminated water. Chem. Commun, 47, 10719-10721.

17. Zewail, T. M., \& Yousef, N. S. (2015). Kinetic study of heavy metal ions removal by ion exchange in batch conical air spouted bed. Alexandria Engineering Journal, 54, 83-90.

18. Zhou, Y. M., Jin, Q., Hu, X. Y., Zhang, Q. Y., \& Ma, T. S. (2012). Heavy metal ions and organic dyes removal from water by cellulose modified with maleic anhydride. Journal of Materials Science, 47, 5019-5029.

19. Zhou, Y. M., Wang, X. H., Zhang, M., Jin, Q., Gao, B., \& Ma, T. S. (2014). Removal of $\mathrm{Pb}(\mathrm{II})$ and malachite green from aqueous solution by modified cellulose. Cellulose, 21, 2797-2809.

20 Zhou, Y. M., Min, Y. H., Qiao, H.,Huang, Q., Wang, E. Z., \& Ma, T. S. (2015). Improved removal of malachite green from aqueous solution usingchemically modified cellulose by anhydride. International Journal of Biological Macromolecules, 74, 271-277. 